Check for updates

Cite this: RSC Adv., 2018, 8, 10715

Received 8th February 2018

Accepted 4th March 2018

DOI: $10.1039 / c 8 r a 01233 d$

rsc.li/rsc-advances

\section{Carbon nanotube-alumina strips as robust, rapid, reversible adsorbents of organics $\dagger$}

\author{
Duoni, (D) Zuoxing Di, Hang Chen, Zefang Yin, Chaojie Cui, Weizhong Qian (D)* \\ and Minghan Han*
}

Developing nanostructured adsorbents of organics is crucial for environmental protection with low energy consumption, but care needs to be taken to prevent the loss of nanomaterials because of their small size. This paper reports the fabrication of carbon nanotube (CNT)-alumina strips (CASs) with a high surface area, sufficient mesopores and strongly interacted structure. Use of CASs allowed the rapid and reversible adsorption-desorption of para-xylene, when compared to pristine powders of CNT and activated carbon. Use of CASs is promising for the practical use when packed in a scaled adsorption tower.
Carbon nanotubes (CNTs), which are $\mathrm{sp}^{2}$ hybridized carbon with a hydrophobic surface property, high chemical stability and exohedral surface, were recently intensively studied for uses as a promising adsorbent for the separation of organics from water, ${ }^{1-10}$ or for the trapping of trace organics in air, ${ }^{11-13}$ which are all challenging issues in environmental protection. Most of the previous work has focused on conceptual separation, and this has probably been because of the limited availability of samples of CNTs. ${ }^{1-10}$ However, there are several challenges involved in the practical application of CNTs in environmental protection. One is that the primary size of a CNT is too small when compared to the size of conventional porous materials, such as activated carbon (AC) and zeolite. Secondly, pristine CNTs were easily carried away with the fluids, if they were used directly. The loss of CNTs is unacceptable, considering their current high cost and the safety risk for humans from directly breathing them in ref. 14 and 15. Such drawbacks of nanomaterials were noticed early on and the fabrication of a macroscopic structure of CNT or graphene by various methods was proposed for different applications. ${ }^{16-23}$ However, the macroscopic structure should remain stable under the operating conditions for adsorption methods, especially during scale up of the method. This is not an easy task, because the macroscopic structures of CNTs or graphene always swelled after adsorbing organics, ${ }^{6,7,24}$ resulting in an unstable or even failed operation. In addition, the structures of CNT-based adsorbents should meet the requirements of reversible utilization in adsorption and desorption performance, ${ }^{24}$ because their cost is too high to use them only once.

Department of Chemical Engineering, Tsinghua University, Beijing 100084, China. E-mail: qianwz@tsinghua.edu.cn; Hanmh@tsinghua.edu.cn

$\dagger$ Electronic supplementary information (ESI) available. See DOI: $10.1039 / \mathrm{c} 8 \mathrm{ra} 01233 \mathrm{~d}$
In this paper, the fabrication of mesoporous CNT-alumina strips (CASs) with high strength is proposed. The idea is to enhance the interaction of CNT and alumina $\left(\mathrm{Al}_{2} \mathrm{O}_{3}\right)$, in order to increase their strength, by using a processing technology. The structure of the CASs was maintained well after absorbing organics (para-xylene, PX), but the structure of CNTcarboxymethyl cellulose (CMC) strips was not. More specifically, the porous alumina of CASs does not influence the surface area of CNT, but provides sufficient transfer channels, allowing the rapid, reversible adsorption-desorption of organics, when compared to powders of pristine CNT and AC. In addition, CASs with a higher bulk density provided an effective packing in an adsorption tower for high throughput treatment of organics with constant bed pressure drop, compared to the pristine CNTs. This result represented big progress in enhancing the practical applications of CNTs including the trapping of volatile organic compounds (VOCs) and spilled organics.

Experimentally, CNTs were prepared by using a chemical vapour deposition method using cobalt/magnesium oxide $(\mathrm{Co} /$ $\mathrm{MgO}$ ) as catalyst and ethylene as carbon source similar to that in a previous report. ${ }^{25}$ Ethylene was decomposed using $\mathrm{Co} / \mathrm{MgO}(10 \mathrm{~g})$ at $700{ }^{\circ} \mathrm{C}$ in a fluidized bed reactor (quartz with an inner diameter of $50 \mathrm{~mm}$ ), where the mixed gases of ethylene and argon had a volume ratio of $1: 1$ and a gross flow rate of $200 \mathrm{ml} \mathrm{min}^{-1}$. After $30 \mathrm{~min}$, the reaction was stopped and the CNT product was collected and kept under ambient conditions. To make CNTalumina strips, the CNT powder, alumina gel and water with a weight ratio of $1: 1: 2$ was mixed together in a machine with stirring rate of $30 \mathrm{rpm}$ for $2 \mathrm{~h}$. Then the solid mixture was transferred into a twin-squeezer with a hole of $3 \mathrm{~mm}$. The product obtained was a strip with length of $20-30 \mathrm{~cm}$ and a diameter of $3 \mathrm{~mm}$. The samples were cut and dried at $110^{\circ} \mathrm{C}$ for $4 \mathrm{~h}$. Then the sample was calcined at $500{ }^{\circ} \mathrm{C}$ in nitrogen $\left(\mathrm{N}_{2}\right)$ gas for $6 \mathrm{~h}$.

A similar strip of CNT-CMC was prepared following the previously described steps, except CMC powder was used 
instead of alumina gel and the strips obtained were out calcined because of the stability of the CMC. To test the structural ability of CASs in organics, they were immersed into PX for $3 \mathrm{~h}$. Photographic images were obtained before and after adsorption. For the continuous adsorption-desorption cycles, the adsorption was based on $40 \mathrm{~g}$ strips under ambient conditions, while the desorption was performed under vacuum or by direct heating at $100{ }^{\circ} \mathrm{C}$ (Fig. S1, ESI $\dagger$ ).

The as-prepared CNTs were agglomerates with high porosity and a size distribution of 1-20 $\mu \mathrm{m}$ [Fig. 1a, characterization method in Fig. S1 (ESI $\dagger$ )] and the bulk density was about $0.03 \mathrm{~kg}$ $\mathrm{m}^{-3}$. They were composed of many entangled tubes with diameter of 10-30 nm [Fig. $1 \mathrm{~b}$ and S2 (ESI $\dagger$ )]. To make CASs, the alumina gel was uniformly mixed with CNTs. Alumina gel can effectively occupy the voids of CNTs to form a relatively uniform mixture (Fig. 1c). The mixture was extruded as strips (Fig. 1d) of 20-30 $\mathrm{cm}$ long and $3 \mathrm{~mm}$ in diameter and this was followed by drying and calcination. The CASs were cut into $3 \mathrm{~cm}$ long strips for the adsorption experiment.

Results of $\mathrm{N}_{2}$ isothermal adsorption suggested that pristine CNTs and the $\mathrm{Al}_{2} \mathrm{O}_{3}$ skeleton in CASs after burning the CNTs inside had a surface area of $233.2 \mathrm{~m}^{2} \mathrm{~g}^{-1}$ and $232.5 \mathrm{~m}^{2} \mathrm{~g}^{-1}$, respectively. The surface area of the CASs is about $225 \mathrm{~m}^{2} \mathrm{~g}^{-1}$ (Fig. 2a). The pore volumes of the pristine CNTs and alumina skeleton were $1.43 \mathrm{ml} \mathrm{g}^{-1}$ and $1.09 \mathrm{ml} \mathrm{g}^{-1}$, respectively. The formation of CASs resulted in the significant decrease of pore volume and pore width. The pore volume of the CASs was 0.38 $\mathrm{ml} \mathrm{g}^{-1}$, just $35 \%$ of that of the pristine CNT powder. Apparently, the extrusion results in the formation of a strip with a compact structure. Mercury compression results (Fig. S3, ESI $\dagger$ ) suggested that the pores larger than $1 \mu \mathrm{m}$ nearly disappeared.

The ratio of macropores larger than $100 \mathrm{~nm}$ is also very small. The pores of 5-100 $\mathrm{nm}$ contributed to the largest pore volume and the mesopores of 3-5 $\mathrm{nm}$ also contributed to the significant pore volume. Average pore width of CASs was $7.1 \mathrm{~nm}$, far smaller than that $(26.1 \mathrm{~nm})$ of pristine CNTs. Packing density of CASs with $3 \mathrm{~cm}$ in length and $3 \mathrm{~mm}$ in diameter was $0.48 \mathrm{~g} \mathrm{l}^{-1}$, which was comparable to that of the AC. In comparison, pristine CNTs had sufficient stacking pores of 0.1-15 $\mu \mathrm{m}$ (Fig. S3, ESI $\dagger$ ). These results indicated that the

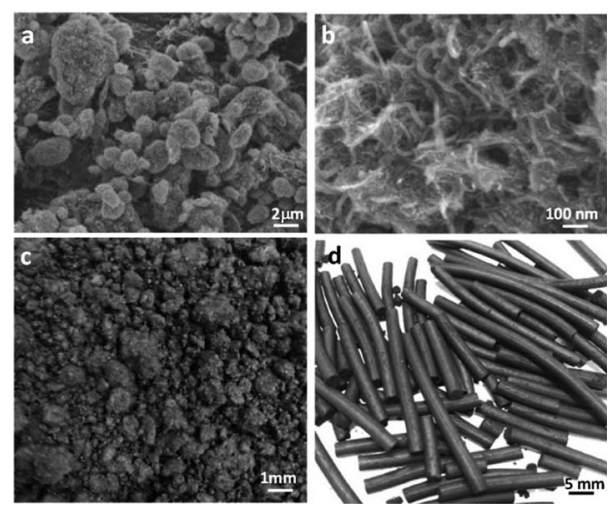

Fig. 1 (a) SEM image of pristine CNT powder, (b) SEM image of CNTalumina strips, (c) optical image of the of mixture of CNT-alumina before extrusion, (d) CNT-alumina strips after extrusion, drying, calcination and cutting.
CASs exhibited both sufficient mesopores and a compact structure, which was very suitable for using the adsorption operation for a long time as discussed later in this paper.

The X-ray diffraction (XRD) results suggested that the asformed alumina belonged to the $\Upsilon$-phase with characteristic $2 \theta$ peaks near $67.00^{\circ}, 45.84^{\circ}$ and $37.59^{\circ}$ (Fig. 2 c). Pristine CNT had an intense $2 \theta$ peak near $26^{\circ}$ and a weak peak at $42.83^{\circ}$. The intensity of the peak at $26.2^{\circ}$ of CNT was retained in CASs, but the intensity of the peak at $42.83^{\circ}$ was weakened. Thermogravimetric analysis (TGA) indicated that pristine CNT had a burning peak at $626{ }^{\circ} \mathrm{C}$ (Fig. 2d). However, the peak was at $615{ }^{\circ} \mathrm{C}$ for the CASs, which validated the interaction between CNT and alumina, and was in agreement with the results of the Fourier-transform infrared spectroscopy characterization (Fig. S4, ESI $\dagger$ ). On the latter spectrum, the peak intensity at $3500 \mathrm{~cm}^{-1}$, associated with the $-\mathrm{OH}$ groups of alumina, decreased significantly, and it was thought that the interaction between alumina and the CNTs consumes these functional groups. Similarly, it has been previously reported that the interaction of alumina and CNTs or graphene resulted in a significant increase of strength and thermal conductivity. ${ }^{\mathbf{2 6 - 2 8}}$ But it was stressed that the improvement of the performance only happened by adding a small amount of CNTs or graphene. In the present work, it was proved that the composite with a weight ratio of CNT to alumina of $1: 1$ exhibited a similar strong interaction and excellent structural stability as discussed next.

The structures of strips of CAS and CNT-CMC, and pristine powder of CNT before and after adsorbing PX are shown in Fig. 3. The pristine powder of CNT became a paste after adsorbing PX (Fig. 3a and b). Results of further experiments indicated that if pristine CNT absorbed too much PX, gravity did affect it and the PX would flow naturally out of the CNT agglomerate. The result proved that although the capillary force resulted in a high intake of organics inside the agglomerate of CNTs, it also resulted in the formation of an unstable pore structure. The disappearance of porosity when CNT powder became a paste, which is unfavourable for treatment in a large size adsorption tower, will be discussed next. Unexpectedly, CNT-CMC strips were completely decomposed after adsorbing

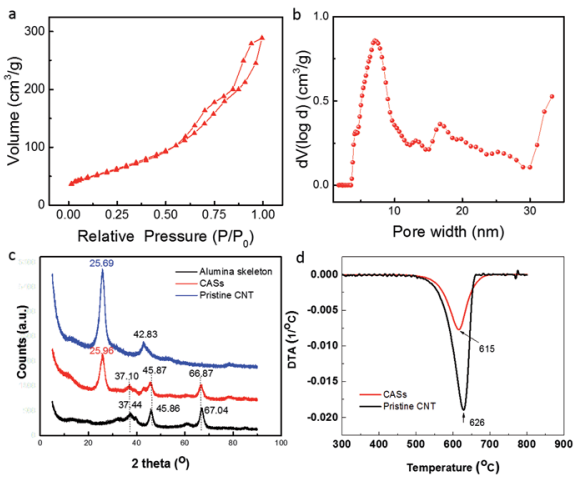

Fig. 2 (a) Isothermal adsorption curve of CASs, (b) pore size distribution of CASs determined using $\mathrm{N}_{2}$ isothermal adsorption, (c) XRD pattern of CASs, pristine CNT powder and alumina skeleton of CASs after burning the CNTs, (d) differential thermal analysis pattern of CASs and pristine CNTs. 
PX (Fig. 3c and d), whereas the CASs retained its original morphology (Fig. 3e and f). Because CMC is an organic material, it will decompose under the temperatures higher than $150{ }^{\circ} \mathrm{C}$. In this case, the CNT-CMC strips were unable to be treated in the same manner as CASs, in which the components of CNT and alumina remained stable enough at a high temperature (up to $2000{ }^{\circ} \mathrm{C}$ ) if they were filled with inert gas. As a result, the interaction between CNTs and CMC is smaller than the interaction between CNT and PX. The fracture of CNT-CMC strips occurred at the adsorption interface, resulting in the formation of various small sized powders and unavoidable loss in use. In sharp contrast, the CASs remained very stable under adsorption conditions and the PX solution remained very clean, implying no loss in solution. In this case, CASs can be effectively packed into an adsorption tower, in the same way as other conventional catalysts or adsorbents used in the industry.

Next, the desorption efficiency of CASs, pristine CNT powder and AC were compared (Fig. 4a). The higher desorption ratio, the greater the possibility of the adsorbents being able to be used for long time and to be reliable in use. High temperature purging was used for pristine CNT powder with a relatively low desorption rate. It took $30 \mathrm{~min}$ to achieve the desorption ratio of $40 \%$ and $120 \mathrm{~min}$ to achieve 99\% desorption. The slow desorption is related to the significant change in pore structure and volume of CNT, which firstly is in a gel state which then shrunk to a rigid structure in the final stage. Vacuum desorption can be used in the initial stage for CASs, pristine CNT and AC, which exhibited similar desorption rate to CASs in the desorption ratio range of $0-40 \%$. After that, vacuum desorption showed a low efficiency with pristine CNT and AC. Then high temperature gas purging was used but it required a much longer time for complete desorption. It took 70 minutes to achieve a desorption ratio of $96 \%$ (75 min in total) from $40 \%$ (5 min in total) for pristine CNT. However, it is impossible to achieve a desorption ratio higher than $90 \%$ for AC within 75 min. The

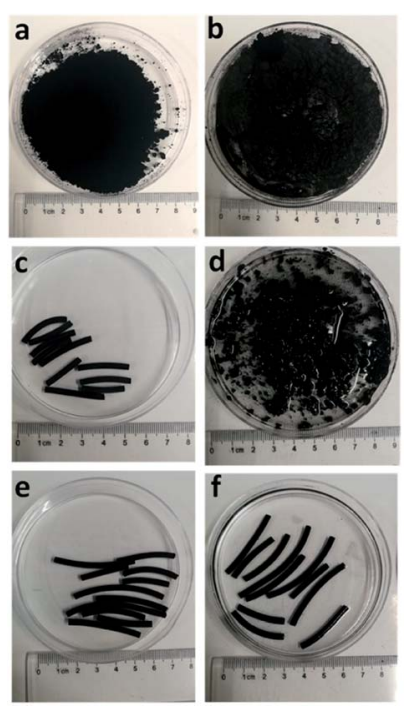

Fig. 3 (a) Pristine CNTs. (b) CNTs after adsorbing PX. (c) CNT-CMC strips. (d) CNT-CMC after adsorbing PX. (e) CASs. (f) CASs after adsorbing $\mathrm{PX}$. desorption ratio increased very slowly in the range of $80 \%$ at $30 \mathrm{~min}$ to the maximal $87 \%$ at $75 \mathrm{~min}$. Apparently, the presence of dominant micropores is unfavourable for rapid desorption with AC, compared to CASs or pristine CNTs. In sharp contrast, vacuum desorption was always feasible for the CASs, the desorption ratio of PX was nearly $100 \%$ and was completed within $20 \mathrm{~min}$. Apparently, CASs with fixed structure stability and a large number of mesopores allowed much quicker desorption than that of pristine CNT with an unstable pore structure during adsorption. Thus, it is possible to use CASs to match the adsorption time and desorption time (Fig. 4b), which is favourable for the simplification of the operation. For CNT powder, the adsorption capacity of PX with pristine CNT will drop by $50 \%$ after a much longer time (Fig. $4 \mathrm{c}$ ), because of the decrease of unstable pores. Meanwhile, the bulk density of CNTs will increase by three times that of the original. When the adsorption capacity of CNTs remained nearly unchanged, the adsorption and desorption of PX was also performed for 10 cycles (Fig. 4d). It exhibited the characteristics of quick adsorption and slow desorption, even using the combined operations of vacuum desorption and high temperature gas purging (Fig. 4a).

The comparisons proved that the use of CASs will have a low energy consumption and be time saving. In addition, the structure of the CASs did not change at all after ten adsorptiondesorption cycles. No structure leakage was observed in the repeated cycles.

In addition, the scale up of an adsorption tower with different adsorbents was also calculated. The Ergun equation was mostly widely used for the prediction of the pressure drop of the packed bed, including the catalytic convertor and adsorption tower. ${ }^{29}$ Generally, the pressure drop of the bed $(\Delta P)$ is linear to $(1-\varepsilon)^{2} / \varepsilon^{3}$ with a lower velocity of fluids and is linear to $(1-\varepsilon) / \varepsilon^{3}$ when the velocity of flow is high. Here, the linear
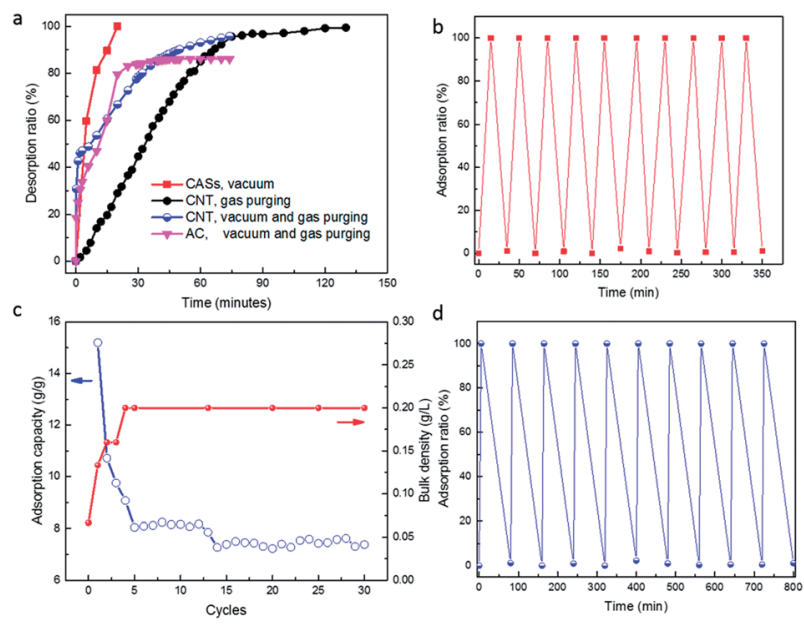

Fig. 4 (a) Time-dependent desorption ratio of PX with different adsorbents. (b) 10 cycles of adsorption-desorption of PX with CASs. (c) Variation of the adsorption capacity of PX and bulk density of CNT powder in different cycles. (d) 10 cycles of adsorption-desorption of PX with CNT powder when its adsorption capacity remained unchanged, using the combined operation of vacuum desorption and high temperature gas purging. 
relationship between $\Delta P$ and $(1-\varepsilon)^{2} / \varepsilon^{3}$ was used for the estimation of the adsorption performance of CASs or pristine CNT, because their desorption rate is not so high and the velocity of fluids is low. For CASs with a fixed structure, the void of the bed $(\varepsilon)$ was about 0.5 and the value of $(1-\varepsilon)^{2} / \varepsilon^{3}$ was 2 . For the pristine CNT, the void of the bed $(\varepsilon)$ was about 0.8 and the associated value of $(1-\varepsilon)^{2} / \varepsilon^{3}$ was about 0.078 . However, as suggested by the results shown in Fig. 4c, the volume of CNT will shrink to the one-third of the original after repeated use, resulting in the effective void $(\varepsilon)$ of the bed decreasing to 0.25. As a result, the value of $(1-\varepsilon)^{2} / \varepsilon^{3}$ was 36 . The pressure drop of the bed $(\Delta P)$ apparently exceeded the designed range for an adsorption tower. In effect, the CNT powder became a bulk material after desorption by heating (Fig. S5 $\dagger$ ). The size of the CNT bulk (in Fig. S5†) was apparently larger than that of CASs, which resulted in a high bed pressure drop or the shortcut of some gases from the leakage of these irregular CNT bulk. In addition, the pressure drop was measured in a tower with $150 \mathrm{~mm}$ in diameter packed with $963 \mathrm{~g}$ CASs with a bed height of $24 \mathrm{~cm}$ (Fig. S6†). The CASs remained very stable in high gas velocities and the pressure drop of the bed was small. In contrast, pristine CNTs were directly carried away by the gases, resulting in a huge loss. Even worse, the wetting of the CNT powder resulted in the formation of slurry. The pressure drop of the bed was unmeasurable, the gas was unable to be fed into the slurry. This means that the direct packing of the CNT powder was unable to meet the requirements for industrial operation, but the CASs did. That is to say, in order to continue using the CNT bed after volume shrinkage, the velocity (throughput) of fluids (PX in the present work) should be decreased. The comparison suggested that it is possible to use CASs for effective packing and for the treatment of fluids with high throughput. In addition, the maximal intake of PX in CASs was $750 \mathrm{mg} \mathrm{g}^{-1}$. This value is high enough for the use in the trapping of VOCs. A related investigation is underway.

In summary, CNT-alumina strips were fabricated using mixing, extrusion, drying and calcination. The processing techniques allowed alumina and CNT to exhibit a strong interface interaction, when compared to the use of CNT-CMC strips. CASs with a stable structure had sufficient mesopores and surface area, and exhibited excellent capability to remove organics with a rapid and reversible operation, compared to pristine CNT and AC. This shows great promise for practical applications in the future.

\section{Conflicts of interest}

There are no conflicts to declare.

\section{Acknowledgements}

The authors are grateful for the financial support of the Beijing Key Project (Z161100002116012) and the National Key R\&D Program of China (2016YFA0200102).

\section{Notes and references}

1 O. G. Apul and T. Karanfil, Water Res., 2015, 68, 34.
2 J. Gao, D. D. Xu, L. L. Ma, Y. Chen and Q. Y. Liu, New Chem. Mater., 2011, 39, 6-8.

3 K. Yang, X. Wang, L. Zhu and B. Xing, Environ. Sci. Technol., 2006, 40, 5804-5810.

4 C. H. Lee, N. Johnson, J. Drelich and Y. K. Yap, Carbon, 2011, 49, 669-676.

5 Q. Ma, H. Cheng, A. G. Fane, R. Wang and H. Zhang, Small, 2016, 12, 2186-2202.

6 X. C. Gui, J. Q. Wei, K. L. Wang, A. Y. Cao, H. W. Zhu, Y. Jia, Q. K. Shu and D. H. Wu, Adv. Mater., 2010, 22, 617-622.

7 X. C. Gui, H. B. Li, K. L. Wang, J. Q. Wei, Y. Jia, Z. Li, L. L. Fan, A. Y. Cao, H. W. Zhu and D. H. Wu, Acta Mater., 2011, 59, 4798-4804.

8 Y. Si, J. Yu, X. Tang, J. Ge and B. Ding, Nat. Commun., 2014, 5, 5802.

9 X. C. Dong, J. Chen, Y. W. Ma, J. Wang, M. B. Chan-Park and X. M. Liu, Chem. Commun., 2012, 48, 10660-10662.

10 J. Q. Nie, Q. Zhang, M. Q. Zhao, J. Q. Huang, Q. Wen, Y. Cui, W. Z. Qian and F. Wei, Carbon, 2011, 49, 1568-1580.

11 S. Chatterjee, M. Castro and J. F. Feller, Sens. Actuators, B, 2015, 220, 840-849.

12 J. F. Feller, N. Gatt, B. Kumar and M. Castro, Chemosensors, 2014, 2, 26-40.

13 P. Slobodian, P. Riha, P. Cavallo, C. A. Barbero, R. Benlikaya, U. Cvelbar, D. Petras and P. Saha, J. Nanomater., 2014, 2014, 589627.

14 J. Kayat, V. Gajbhiye, R. K. Tekade and N. K. Jain, Nanomedicine, 2011, 7, 40-49.

15 L. C. Ong, F. F. Chung, Y. F. Tan and C. O. Leong, Arch. Toxicol., 2016, 90, 103-118.

16 D. N. Futaba, K. Hata, T. Yamada, T. Hiraoka, Y. Hayamizu, Y. Kakudate and S. Iijima, Nat. Mater., 2006, 5, 987-994.

17 S. Jin, W. Z. Qian, Y. Liu, F. Wei, D. Z. Wang and J. C. Zhang, Aust. J. Chem., 2010, 63, 131-134.

18 C. Zheng, W. Z. Qian, C. J. Cui, Q. Zhang, Y. G. Jin, M. Q. Zhao, P. H. Tan and F. Wei, Carbon, 2012, 50, 51675175.

19 X. W. Yang, C. Cheng, Y. F. Wang, L. Qiu and D. Li, Science, 2013, 341, 534-537.

20 J. Zou and F. Kim, Nat. Commun., 2014, 5, 5254.

21 H. Sun, Z. Xu and C. Gao, Adv. Mater., 2013, 25, 2554-2560. 22 L. L. Jiang, L. Z. Sheng, C. L. Long, T. Wei and Z. J. Fan, Adv. Energy Mater., 2015, 1500771.

23 J. Wang, Z. Shi, J. Fan, Y. Ge, J. Yin and G. Hu, J. Mater. Chem., 2012, 22, 22459.

24 H. Chen, W. Z. Qian, X. Qing and X. S. Cheng, Carbon, 2017, 116, 409-414.

25 C. J. Cui, W. Z. Qian and F. Wei, Acta Phys.-Chim. Sin., 2011, 27, 2462-2468.

26 G. D. Zhan, J. D. Kuntz, J. L. Wan and A. K. Mukherjee, Nat. Mater., 2003, 2, 38-42.

27 W. Yu, H. Q. Xie, L. Q. Yin, J. C. Zhao, L. G. Xia and L. F. Chen, Int. J. Therm. Sci., 2015, 91, 76-82.

28 H. Porwal, P. Tatarko, S. Grasso, J. Khaliq, I. Dlouhy and M. J. Reece, Carbon, 2013, 64, 359-369.

29 S. Ergun, Chem. Eng. Prog., 1952, 48, 9-94. 